\title{
Derechos humanos, comisiones de la verdad y nuevas ficciones globales
}

\author{
Human Rights, Truth Commissions and New Global Fictions \\ Direitos humanos, comissões da verdade e novas ficções globais
}

\section{Fernando J. Rosenberg}

BRANDEIS UNIVERSITY, ESTADOS UNIDOS

Profesor asociado de Estudios Hispánicos y Literatura Comparada en Brandeis University. PhD en Literatura, Johns Hopkins University. Autor de Avant-Garde and Geopolitics in Latin America (Pittsburgh University Press, 2006), y de numerosos artículos publicados en revistas especializadas. Su libro After Human Rights: Literature, Film and Visual Arts se encuentra en proceso de revisión. Correo electrónico: ferosen@brandeis.edu 


\section{Resumen}

Este ensayo discute la influencia del paradigma parajurídico de la "verdad y reconciliación", prevalente dentro del clima geopolítico de las últimas dos décadas del siglo XX en varias novelas latinoamericanas recientes que tematizan procesos históricos paralelos, localizados en contextos nacionales diferentes como Perú, Chile y Guatemala. El reconocimiento de estas novelas con los más importantes premios literarios en español, manejados desde conglomerados editoriales españoles, señala una intricada relación entre la promoción de un mercado literario panhispano y la proyección de un imaginario político-jurídico global.

Palabras clave: ley; literatura; mercado literario; transición democrática; Alonso Cueto; Santiago Roncagliolo; Madrid Carlos Franz; Horacio Castellanos Moya; Daniel Alarcón; Jorge Volpi

\section{Abstract}

This essay discusses the influence of the paralegal paradigm of "truth and reconciliation" prevalent in the geopolitical climate of the last two decades of the 20th century in several recent Latin American novels. These novels take as a central topic parallel historical processes, set in different national contexts such as Peru, Chile and Guatemala. The fact that these novels are awarded the most important literary awards in Spanish -awards managed by Spanish editorial conglomeratesshows there is an intricate relationship between promoting a panhispanic literary market and projecting a global political-legal imaginary.

Keywords: law; literature; literary market; democratic transition; Alonso Cueto; Santiago Roncagliolo; Madrid Carlos Franz; Horacio Castellanos Moya; Daniel Alarcón; Jorge Volpi

\section{Resumo}

Este ensaio discute a influência do paradigma parajurídico da "verdade e reconciliação" prevalente dentro do clima geopolítico das duas últimas décadas do século XX em vários romances latino-americanas recentes que tematizam processos históricos paralelos, localizados em contextos nacionais diferentes como o Peru, o Chile e a Guatemala. O reconhecimento destes romances com os mais importantes prêmios literários em espanhol, manejados desde conglomerados editoriais espanhóis, aponta para uma intricada relação entre a promoção de um mercado literário pan-hispano e a projetação de um imaginário político-jurídico global.

Palavras-chave: lei; literatura; mercado literário; transição democrática; Alonso Cueto; Santiago Roncagliolo; Madrid Carlos Franz; Horacio Castellanos Moya; Daniel Alarcón; Jorge Volpi

RECIBIDO: 13 DE MARZO DE 2014. APROBADO: 1 DE ABRIL DE 2014. DISPONIBLE EN LÍNEA: 30 DE JULIO DE 2014.

\section{Cómo citar este artículo:}

Rosenberg, Fernando J. "Derechos humanos, comisiones de la verdad y nuevas ficciones globales". Cuadernos de Literatura 18.36 (2014): 141165. http://dx.doi.org/10.11144/Javeriana.CL18-36.dhcv 
SE HABL A HOY de la narrativa y el cine de la violencia contemporánea, una nueva configuración que supone una serie de corrimientos del papel del estado como centro gravitacional del conflicto social y como escenario de la consumación de una justicia por venir, un escenario en donde el mercado se postula (o se había postulado desde la introducción de las recetas neoliberales hasta su espectacular fracaso) como la racionalidad última. Pero las formaciones culturales ya no se reemplazan y/o superan, sino que coexisten en un presente fragmentado de capas superpuestas (un tiempo ni dialéctico ni teleológico) ${ }^{1}$. Persiste y resurge entonces todo un corpus narrativo que vuelve sobre una violencia históricamente anterior, la de las guerras sucias en las que la nación funcionaba como marco semántico de la violencia y del sacrificio, pero desde la perspectiva de sus consecuencias y efectos; lo cual también constituye una reevaluación de lo que en ciertos contextos se dio en llamar la "transición", en la que el marco metajurídico de los derechos humanos ofició de discurso para la legitimación y reconstitución del estado democrático². Pero esta transición también ha sido entendida como el sello legitimador que cierra el ciclo geopolítico realizado por las dictaduras, es decir, la neoliberalización de las economías latinoamericanas, y la mercantilización ("flexibilización") creciente de la vida bajo el signo triunfante de la globalización y la desregulación del capital, en la ya tan lejana década de los noventa ${ }^{3}$.

Es desde este entrecruzamiento de problemas que me parece interesante leer estas narrativas que llamaré aquí "de verdad y reconciliación", no porque busquen o supongan una o la otra sino más bien porque se alimentan del marco jurídico-institucional transnacional que promovió las comisiones en diferentes contextos nacionales pero en el mismo clima geopolítico global ${ }^{4}$. Más que como expresión de una ciudad letrada comprometida en tramitar los problemas de la nación, leemos estos relatos dentro de una gramática transnacional

1 Esta idea se la debo a los últimos trabajos que Josefina Ludmer leyó en varias ponencias sobre las narrativas del presente, que será el tema de su próximo libro.

2 En el contexto chileno, especialmente, el término fue analizado con mayor riqueza. Véase la compilación editada por Alberto Moreiras y Nelly Richard, Pensar en/la postdictadura.

3 De más está decir que estoy trazando un panorama muy general. Particularmente, quiero aclarar que el uso de la palabra "dictadura" en el caso del Perú es discutible, pero sin duda la militarización de la escena política desde los 80, profundizada con el denominado "autogolpe" o "fuji-golpe" (1992) de Fujimori, dio a este contexto un carácter también dictatorial. La caída de este gobernante y la reconfiguración del Estado democrático que le siguió, incluida la formación de la Comisión de la Verdad y Reconciliación, tienen todas las características de la denominada "postdictadura".

4 Comisión Nacional sobre la Desaparición de Personas en Argentina, para el Esclarecimiento Histórico en Guatemala, de la Verdad en El Salvador, de la Verdad y la Reconciliación en Chile y Perú. 
en la que participa el mercado editorial. Tengamos en cuenta que algunas de las novelas que podrían leerse dentro del marco que estoy trabajando encuentran una llamativa recepción tanto en el mercado hispanoparlante administrado mayormente desde España (desde donde se decide qué autores trascenderán las fronteras nacionales) como en el mercado de los pocos libros en español que consiguen ser traducidos al inglés. Tal es así que estas novelas entran en el circuito más prestigioso de consagración: La hora azul (2005) de Alonso Cueto, premio Herralde de novela; Abril rojo (2006) de Santiago Roncagliolo, premio Alfaguara (cuya edición en inglés fue lanzada por Pantheon en el); mientras que el chileno residente en Madrid Carlos Franz ganó con El desierto (2005) el Premio La Nación-Sudamericana (la editorial argentina de mayor proyección transnacional, ahora parte del conglomerado internacional Random House Mondadori). Como dato complementario, se podría mencionar que otras novelas del corpus han tenido una notable acogida en el mercado norteamericano: Insensatez (2004) de Horacio Castellanos Moya fue traducida al inglés como Senselessness y editada por la prestigiosa casa New Directions, mientras que Lost Gity Radio (2007), escrita en inglés, del peruano-norteamericano Daniel Alarcón, ha recibido la atención de los medios literarios de mayor relevancia.

Sin duda cabría agregar otras novelas a esta lista. En busca de Klingsor (1999) de Jorge Volpi (que ganó el Premio Biblioteca Breve de Seix Barral de 1999) podría figurar aquí ya que, si bien se centra en Estados Unidos y Alemania después de la segunda guerra, puede leerse a la luz de las conexiones entre los juicios de Nüremberg y el surgimiento de la narrativa de los derechos humanos, que está en el sustrato histórico de las otras novelas. Nüremberg introduce en el derecho internacional la figura de los "crímenes contra la humanidad" o "de lesa humanidad", con lo cual se desglosa el crimen (de genocidio) de la razón soberana o la razón de estado, reenmarcando así los límites jurisdiccionales. Se abren de esa manera las fronteras al escrutinio externo (de organizaciones internacionales, gubernamentales o civiles) sobre las políticas emprendidas por los gobiernos respecto a los habitantes de un territorio, y se le quita entonces peso a la autoridad no solo del soberano sino también de las mayorías.

Recordemos que en buena parte de los contextos nacionales esta transición se significó como una operación pedagógica que suponía la superación de la "cultura de la violencia", para dar paso a un nuevo contrato social basado en la tolerancia. Sin ser estrictamente equivalentes, estos desarrollos - la restauración del estado de derecho y de las protecciones civiles bajo el auspicio internacional de los derechos humanos, y la legitimación de una creciente incorporación de las economías nacionales al capitalismo financiero internacional- se intersectan 
en diversos puntos. Para sugerir solo algunos de estos puntos, digamos que los dos desarrollos suponen el discurso hegemónico del liberalismo que coloca al individuo y a la comunidad en una relación confrontativa; que este discurso hegemónico supone el abandono del programa de la izquierda tradicional y un desprestigio o una simple desarticulación de categorías como "clase" y "pueblo"; que ambos suponen la existencia de redes internacionales gubernamentales y no gubernamentales, que ejercen creciente presión sobre los que antes eran considerados asuntos internos; que ambos desarrollos suponen un creciente fetichismo u objetificación de las relaciones sociales que paradójicamente sostiene al discurso aparentemente emancipador de los derechos individuales como manera de mediatizar la relación individuo-sociedad; que ambos suponen una "judicialización de la política", en la que ciertas demandas sociales pasan por canales judiciales, complementada por una desjudicialización del espacio público, un retiro del estado de algunos de sus roles históricos (O’Donnell); que ciertas reformas legales promovidas internacionalmente participan de un discurso que iguala la libre empresa con la libertad del individuo, y que entidades como el Banco Mundial, el FMI y el Banco Interamericano de Desarrollo han ejercido presión para efectuar la reforma judicial que permitiera la fluidez de capitales (Domingo y Sieder; Sieder et al.), etc. Estas intersecciones son solo algunas vías para pensar el anudamiento entre los derechos humanos y la globalización financiera. Y una pregunta que insiste, al nivel ahora de los imaginarios sociales: ¿Cómo la imaginación de una humanidad por venir que los derechos humanos prometen (ya que no se trata de la universalidad existente sino de otra posible) logra neutralizar simbólicamente el empobrecimiento desigual de la vida de una humanidad efectivamente lograda por una globalización que supone la mercantilización de la existencia y su concomitante producción desigual de residuos? Creo que esta neutralización imaginaria está implícita en el relativo éxito de mercado de este corpus, al mismo tiempo que cada novela confirma y responde más o menos críticamente a dicha promesa.

Las preguntas de este ensayo están dirigidas entonces a analizar la persistencia o el retorno de la narrativa postdictatorial, con un implícito cuestionamiento a los marcos teóricos utilizados para pensar este corpus. Sin desmerecer la pertinencia de categorías como duelo, trauma y memoria, ni subestimar la capacidad de la forma novelística para contribuir a estos procesos socio-culturales, estos marcos tienden a psicologizar y al hacerlo proyectan a la nación como entidad discreta y orgánica, mónada autotélica y autónoma, pensada en base al modelo del individuo burgués. Complementariamente, se podría decir que no se trata en estos casos de novelas postdictatoriales como las entiende Idelber Avelar, porque no se ocupan de hacer el duelo por proyectos sociales perdidos, un 
duelo que estaría en disonancia con la euforia neoliberal, con la mercantilización de la vida que constituye el programa socio-económico triunfante de las dictaduras y que las democracias legitimaron. Estos cambios paradigmáticos implicaron, como se sabe, la desarticulación del nudo que ligaba a la literatura con la constitución hegemónica del estado. Si la narrativa postdictatorial está marcada, para Avelar, por un doble duelo (el de los proyectos sociales derrotados y el de la literatura como lugar privilegiado en donde se dirimen los proyectos sociales), el tipo de inserción en el mercado de este cuerpo de novelas que aquí trabajo señala una agenda divergente. Quiero entonces pensar estas novelas desde la perspectiva de la movilización del imaginario de los derechos humanos como un discurso global que se concibe como superación de la política, y la manera en que ellas alimentan o desalientan esa ilusión. Si entendemos que en cierta medida el mercado cultural global había explotado una imagen de Latinoamérica como región salpicada de coloridas revoluciones permanentes e inconclusas desde el boom, la "novela de verdad y reconciliación" satisface el nuevo imaginario global de la postpolítica. Estas novelas pueden estar confirmando el fin de la era de las revoluciones desde el lugar mismo en que la utopía revolucionaria se suponía preservada, pero desplazando la carga utópica hacia la agenda de los derechos humanos, que autoriza y reproduce una división geopolítica de modernidades cumplidas o pendientes, ahora con los derechos humanos como medida universal.

El efecto de lectura en el mercado del primer mundo de este corpus de nueva literatura latinoamericana renegaría entonces del nihilismo de base en el que el paradigma de los derechos humanos se constituye; es decir, de que los derechos humanos son el resultado de una crisis de confianza de la modernidad europea en su propia razón instrumental luego de la segunda guerra, una operación de rescate del programa iluminista en el momento de mayor desilusión (Ignatieff 65), un fetiche que desestima su falla al mismo tiempo que la reconoce y señala. Paradójicamente, los derechos humanos han sido pensados después de los años sesenta como los derechos de otros, en una lógica planetaria que Jacques Rancière - quien por otra parte defiende los derechos humanos, o una lectura de estos como la irrupción de lo inesperado, de los que no cuentan para el campo administrado de la política - ha ilustrado irónicamente con la imagen de la ropa vieja donada a la caridad. Estas novelas, especularemos aquí, pueden ser leídas como una modesta carta de agradecimiento por el gesto. Pero mientras el desencanto con el estado latinoamericano tiene raíces históricas múltiples (en su constitución como agente de poder de las elites, en su incapacidad para incorporar las diversas luchas sociales en su ámbito, en su mera ineficiencia, etc.), diferentes a la crisis de la modernidad central y a la reconstitución geopolítica 
que da nacimiento tanto a los derechos humanos como a la guerra fría, hay que tener en cuenta que estos también se rearticulan y se reinventan en Latinoamérica, como respuesta a una crisis que corresponde al fin de la guerra fría, y para articular demandas que no estaban anticipadas en el discurso de los derechos. Efectivamente, los derechos humanos también han abierto un espacio y prestado un lenguaje para causas que no estaban en principio contempladas dentro de su marco y de su modo de inserción en Latinoamérica como protección contra abusos cometidos por el estado.

Por otro lado, y complementariamente, el consumo internacional de estas narrativas podría responder a una nostalgia, la nostalgia por lo que nunca ocurrió, particularmente si se piensa en el caso de España, cuya memoria histórica de la guerra civil y de los crímenes del franquismo nunca fue examinada judicialmente, cuyas fosas comunes (un sitio paradigmático que aparece en muchas de estas novelas) nunca fueron exhumadas, cuyos niños robados nunca restituyeron su identidad, etc. Dígase de paso que el intento reciente del juez Baltazar Garzón de promulgar procesos elevados por familiares de las víctimas del franquismo fue recibido con enorme oposición ${ }^{5}$. Lo cual es sintomático, claro está, dado que el ejercicio del derecho internacional que este mismo juez ha movilizado en defensa de los derechos humanos parece excluir la posibilidad de llevar a la justicia los crímenes masivos perpetrados dentro de la jurisdicción tradicional del propio

5 Nada hay de sorprendente, desde el punto de vista latinoamericano, en los argumentos esgrimidos para oponerse a esta resolución judicial: "se abren viejas heridas", "la transición se basó en la reconciliación entre vencedores y vencidos", "los republicanos también cometieron abusos", etc. Lo claramente diferente es su temporalidad. Sucintamente lo resume el profesor Vincenç Navarro en su editorial para El País: "Como era de esperar cuando un juez español de la Audiencia Nacional, Baltasar Garzón, que intentó en su día enjuiciar al general Pinochet por sus crímenes en contra de la humanidad, ha intentado hacer lo mismo y enjuiciar a los autores del alzamiento fascista en contra de la República española, responsables de crímenes en contra de la humanidad en España, muchas voces se han alzado en contra de tal enjuiciamiento. Los argumentos utilizados han variado. Uno de los más frecuentes es que tal juicio reabriría las heridas supuestamente cerradas durante la transición, argumento que se utiliza sobre todo por los herederos de los autores que infligieron tales heridas con el objetivo de que se olviden los crímenes que realizaron. No desean que se conozcan y condenen las enormes crueldades que sus antecesores hicieron, llevándolos a los tribunales, tal como se ha hecho en otros países europeos que sufrieron el nazismo y el fascismo, como Italia, Alemania y Francia (con las autoridades del Gobierno colaboracionista de Vichy). [...] me temo que tal juicio no tendrá lugar como consecuencia del enorme poder que los vencedores tienen en España, cuyo jefe de Estado, el Monarca, ha indicado en repetidas ocasiones que no tolerará que se hable mal en su presencia del general Franco. Me temo que España continuará siendo el único país de Europa que no enjuiciará a los golpistas asesinos. Después de todo, como se decía durante la dictadura, Spain is different". 
territorio nacional. Siguiendo esta línea, podría pensarse que la literatura de algunos de los autores latinoamericanos de mayor circulación en el ámbito europeo operaría como conveniente substituto o fármaco que asegura fantasmáticamente cierta inmunidad contra sitios negados de la propia memoria y de la propia responsabilidad histórica.

Si bien las llamadas "comisiones" (de la verdad, de la verdad y la reconciliación, de derechos humanos, etc.) difieren drásticamente entre sí (tanto en cuanto a su constitución, inserción y función como a sus consecuencias), son inseparables del marco internacional de los derechos humanos, aun cuando se encuentren lejos de estar contenidas en estos. Si el poder performático del discurso de los derechos humanos se basa en su autopostulación como exterioridad imaginaria a toda afiliación política, por otro lado es claro que su promoción en las últimas dos décadas del siglo Xx fue un factor de la judicialización de la política que canaliza un escepticismo hacia toda metanarrativa centrada en el cambio revolucionario del estado. Mientras que los derechos humanos en su inicio contienen el reconocimiento de una crisis al mismo tiempo que prometen su superación, estas comisiones paraestatales proyectan una reconstitución de la estatura moral y la promesa emancipadora del estado latinoamericano al borde mismo de su deslegitimación, al fin de las dictaduras y guerras civiles. Las comisiones, como organismos que están dentro y fuera del estado, como organizaciones extrajudiciales y a veces extraestatales (Guatemala, El Salvador), reconocen la pérdida de la centralidad del estado, de su legitimidad como lugar privilegiado de la justicia por venir, a la vez que son un intento paradójico de restitución de ese lugar - paradójico porque el suelo epistémico no es una reconstitución del etnos sino la narrativa transnacional de los derechos humanos que está cargada de una historia de protección del individuo contra un estado perpetrador-.

Entonces, si los derechos humanos están ya fundados en la negación de esta pérdida de fe, si son ya de por sí un acto de restitución que contiene (en el doble sentido de integrar y resistir) el fracaso del proyecto moderno, su movilización para la construcción de una imaginación global de la periferia latinoamericana se revela problemática. Implica una renegación (en el sentido freudiano de des-conocer) de la pérdida de fe, una proyección de un lugar en el mundo en donde la modernidad completa no es ya una ruina sino una esperanza, algo cuyo advenimiento es deseable. Cada una de las novelas leídas contiene elementos de este escepticismo y de esta invocación de los derechos humanos como operación de rescate. Pero el lugar abierto por los derechos humanos puede ser reimaginado como una estrategia flexible para preservar la posibilidad de 
la justicia al cuestionar el sistema legal, y la ilusión postpolítica de los derechos puede proporcionar un lenguaje para la continuidad de las causas políticas.

En estas coordenadas múltiples se insertan una serie de relatos que, en su circulación transnacional, permiten lecturas múltiples y situadas, que atraviesan los diversos mapas de la imaginación política contemporánea. Voy a hacer un recorrido bastante somero por cuatro de estas novelas, sugiriendo puntos de análisis que se saben parciales, ya que dejan conscientemente algunos aspectos de ellas sin tocar. Pero creo que esta exposición extensa más que intensa sirve para entender el surgimiento y la circulación de estos relatos y presta un marco para considerarlos como un nuevo corpus, y para leer otras novelas que no estoy estudiando explícitamente.

Comenzaré por la novela del chileno Carlos Franz, El desierto. Se trata aquí de la historia del regreso a Chile y a su pueblo, Pampa Hundida, desde su exilio alemán, de una exjueza de provincia, Laura Larco, joven talento legal en el momento de la presidencia de Salvador Allende y convertida a fuerza de exilio y desencanto en una filósofa del derecho y profesora de la Freie Universität en Berlín. El regreso está determinado por la interpelación de la joven hija de la jueza, Claudia, nacida y crecida en Alemania pero concebida en Chile, quien, luego de recibir una instrucción básica sobre las violaciones de derechos humanos durante la dictadura de Pinochet, cuestiona a su madre sobre su implicación personal a lo largo de los primeros meses del régimen ("¿ ¿Dónde estabas tú, mamá, cuando esas cosas horribles ocurrieron en tu ciudad?"[12], frase que oficia de leitmotiv de las disquisiciones de la jueza) y quiere visitar el lugar en donde fue concebida, y en donde su padre vive. Lo que no sabe es que detrás de su padre legítimo, un periodista tan bien pensante como inocuo, se esconde un padre obsceno, el militar que comandaba la ocupación de la zona, y con quien su madre había pretendido luego del golpe hacer un pacto que, lejos de acotar el poder militar, terminaría convirtiéndose en ritual de sometimiento sexual masoquista a este. La trama está tejida a través del relato de los encuentros y desencuentros de la jueza en su retorno y de una larga carta a su hija que está esparcida a lo largo de toda la novela.

Para la exjueza, su país adoptivo es el lugar de la reflexión pura consumada en el ámbito protegido de la esfera académica. Alemania y Berlín no son, obviamente, un suelo neutral desde donde meditar sobre la relación entre ley y violencia, pero en la novela son espacios sorprendentemente vacíos, como si, habiendo ya domesticado a sus propios monstruos, gozaran de una condición posthistórica; y la hija de la jueza puede pensar en la república sudamericana desde la perspectiva de la imaginación global de unos derechos humanos que 
hacen falta pero en otro lugar y que prestan su lenguaje universal para enmarcar la historia local de un país en donde "todavía es posible tener ideales". Al final de la novela, consumado el recorrido de ida y vuelta de madre e hija, esta última termina trabajando en Alemania, como era de esperarse, en una organización de derechos humanos.

Chile es no solo el sitio de concepción de la joven alemana, sino que está en el nacimiento mismo de la filosofía legal de la jueza. Efectivamente, luego de haberse adherido durante el proyecto socialista de Allende a la idea de que se puede comenzar a hacer justicia incluso con leyes injustas, la jueza devenida profesora concibe en su exilio alemán toda una teoría del derecho basada en la figura trágica de la Moira, la historia como pulsión mortal que empuja un destino que acaba con toda ambición racionalmente justa. Alemania oficia de lugar privilegiado de producción intelectual que posibilita que la materia bruta de su biografía sudamericana se consume en una teoría universal y abstracta, en la que derrota, decepción y trauma se transforman en nihilismo político. La novela entonces está organizada desde el supuesto de que los derechos humanos son una buena idea, pero no logran contener cierta carga negativa, un impulso trascendente y transhistórico a someterse al poder obsceno que la jueza prueba en su misma biografía, pues esta remite a la constante presencia militar en la democracia chilena, y encuentra eco en la propia historia alemana, en donde estas elaboraciones parecen ser bien recibidas.

De todos modos, si la agenda de los derechos humanos abre paso a causas que no estaban contempladas en el esquema inicial de protección del individuo contra el estado perpetrador, es posible revertir los argumentos de la jueza desde un punto oscuro del libro, y es su persistente misoginia. El sujeto femenino prueba el gusto del poder únicamente en cuanto se somete pasivamente, y luego justifica la obscenidad de este poder masculino con una máscara transhistórica femenina, Moira, asumiendo así la responsabilidad por la violencia sufrida. Esta lectura posible de la novela supone no solo una apertura del marco de los derechos humanos en sintonía con nuevos modos de agenciamiento, sino que permite pensar una aproximación al poder que no esté cargada de fascinación y espanto.

No es inmediatamente después del golpe de Pinochet cuando la jueza se va de Chile, sino solo cuando se enreda, poco más tarde del golpe, que parece en principio no atentar contra la autonomía judicial, en el funcionamiento del centro clandestino de detención en el que se ejecutan prisioneros luego de un juicio militar sumario (en lo que parece ser una ficcionalización de la infame "Caravana de la muerte"). La "clandestinidad" de este centro es apenas nominal ya que su fuerza amenazante sobre la población depende de hacer obvia su condición 
secreta, y está demasiado cerca de un pueblo que hubiese preferido no enterarse de las torturas y ejecuciones. La capacidad de la jueza de seguir sosteniendo la justicia ante las leyes injustas se ve comprometida por la existencia de un sitio de excepción dentro de la misma jurisdicción que ella quiso imaginar como a salvo del poder militar y la lógica de la guerra interna. Es más, la autonomía judicial defendida se ve aún más comprometida con estos juicios sumarios en los que ley y procedimiento pueden ser el marco de legitimidad del asesinato político, y no toda ley injusta parece contener un núcleo redimible de justicia. A esta situación sigue un pacto perverso con el mayor Cáceres que consiste en la salvación de sus detenidos a cambio de relaciones sexuales con la jueza. Un pacto que el mayor por supuesto no cumple, pero que revela un negociación que solo ocurre en la imaginación de la jueza y en la que su cuerpo funciona como carne sacrificial para preservar la ilusión de una ley que no es una herramienta del poder, de una ley que mantiene una higiénica distancia con la fuerza obscena que la funda. Parece ser justamente el militar quien introduce a la joven jueza en una realidad situada más allá del sueño de una transacción conmensurable, el sueño en que se basa la legalidad, no solo al no respetar el pacto que buscaba mesurar el poder, sino al ponerla a ella cara a cara con el desierto sin límites, que es la tumba sin nombre de los ejecutados y desaparecidos.

Se podría especular que, dado el caso chileno (en donde el estado de excepción instalado en el golpe sobrevive en los primeros diez años de democracia a través de la inmunidad legal que protegía a Pinochet), el concepto de trauma que parece estar en las disquisiciones de la doctora Larco sobre la Moira - figura trágica que retorna, fuerza que persiste y que no se somete a ningún pacto- tuvo un nombre mucho más pedestre y una cara reconocible en la figura del dictador devenido luego "padre de la democracia". El pacto que Laura Larco establece con el mayor Cáceres, que busca trascender la violación convirtiéndola en la moneda de cambio, es una alegoría de la transición pactada con la dictadura, que no puede deshacerse de los términos impuestos por esta y en donde Pinochet logra perpetuarse como el padre de la democracia, a pesar de la Comisión de la Verdad y Reconciliación — que claramente decide renunciar a la primera para sostener la promesa de alcanzar aquella reconciliación que nunca llega ${ }^{6}$ - Y Y las disquisiciones filosóficas de la jueza que busca entender la atracción, la culpa y el amor, la dependencia del sujeto por un poder absoluto y sin concesiones que amenaza destruir toda construcción apolínea, y que tiene nombres cambiantes

6 Véase el artículo de Loveman y Lira, que investiga la tradición chilena de una reconciliación que asume la impunidad. 
como Moira, Venus, Pachamama, o la necesidad, acaban por ser una legitimación y dignificación mitológica, con máscara femenina, del poder militar que remite a la violencia fundadora. Aún más irónico resulta el caso si se tiene en cuenta que la comisión misma estuvo sometida, entre otras limitaciones, a la condición de no mencionar ninguno de los nombres de los perpetradores ${ }^{7}$.

Mientras la joven jueza creyó posible domesticar esta violencia mediante la ley y el pacto, para terminar horrorizada ante el paisaje de su obscenidad sin límites, la filósofa madura regresa a su patria oponiéndose a los pactos de la llamada "transición" porque sabe y reconoce que todo pacto se somete a la voracidad siempre renovada de un poder sin límites. Pero al mismo tiempo sabe que no puede hacer nada, y esta nada está enmarcada en la teoría universal y transhistórica de la propia jueza. La izquierda liberal y legalista que ella representa encuentra entonces una verdad en la violencia fundadora, en el fundamento místico de la autoridad; pero son una verdad y una violencia de las que teme apropiarse y a las que teme desautorizar, porque hacerlo sería mancharse de esa sangre y perder su condición de alma bella. La posición de esta izquierda bien educada es entonces la de la histérica, que adora el poder que le da su razón de ser y se limita a señalar su falla, con lo cual confirma en cada caso su propia impotencia.

$\mathrm{Al}$ contrario de El desierto, en donde los hechos narrados son posteriores a la actuación de la primera comisión chilena, Abril rojo de Santiago Roncagliolo trata de una investigación judicial anterior a los procesos testimoniales y paralegales que la comisión peruana daría a conocer; pero su publicación (como también la de la otra novela peruana que trabajaré luego, La hora azul de Alonso Cueto) es posterior a la actuación de la Comisión de la Verdad y Reconciliación que entrega el informe al presidente Alejandro Toledo y a la población de Ayacucho en agosto del 2003 ("Informe final"). El contexto histórico de estas historias es el periodo en el que el estado había declarado la victoria sobre la guerrilla y dado por oficialmente concluida aquella violencia, cuyas víctimas fueron en su mayoría los sectores indígenas más vulnerables. Abril rojo sucede durante la tradicional celebración de la Semana Santa en Ayacucho, en el año 2000. La fecha es significativa, ya que sobre el fondo de la euforia global por el nuevo milenio se recorta la elección presidencial que le daría un tercer término (autorizado especialmente por una conveniente intervención en el Congreso) a Alberto Fujimori; tercer término que se revelaría breve, ya que acabaría meses después con un

7 Hablo aquí de la comisión Rettig, que ofició en 1991-1992. La novela está escrita, según consigna el autor, entre el 2000 y el 2004, momento de actuación de una segunda comisión, la Comisión Nacional sobre Prisión Política y Tortura. Para más detalles, véase Loveman y Lira (66-68). 
escándalo de coimas al nivel más alto y la fuga del presidente (quien renunciaría a su cargo por fax), rechazada por un Congreso que lo destituiría inmediatamente.

En la novela, el discurso de la victoria sobre la guerrilla es continuamente reforzado por las autoridades civiles y militares, mientras se perpetúa una serie de asesinatos brutales que el protagonista, un fiscal menor llamado Félix Chacaltana Saldívar, investiga y que remiten por un lado a cierto exceso espectacular que caracterizó la violencia practicada por Sendero Luminoso y por otro a referencias mitológicas andinas. El fiscal fracasa en su intento de dar con una causa ya que se ve enredado en la trama misma que es el objeto de su búsqueda, por lo que él mismo se transforma de sujeto en objeto de la investigación, sin capacidad entonces de sostener una posición de exterioridad simbólica. Lo que atenta contra su capacidad investigativa es, además de su personalidad pusilánime, la división entre el acento en la legalidad y el procedimiento que el fiscal vehementemente sostiene para sorpresa y escándalo de todos, por una parte, y las reglas y los hábitos tácitos de las instituciones establecidas (ejército, policía), que resultan mucho más poderosas que cualquier norma jurídica, y que funcionan amparadas por un estado de perpetua excepcionalidad. Esta división que aparece en la novela, o sea el desglosamiento institucionalizado y sobreentendido entre, por un lado, una ley impotente $y$, por el otro, una fuerza sin ley, fue particularmente tajante en el Perú, particularmente si se tiene en cuenta que toda la actuación represiva e indiscriminada del ejército sucedió dentro de un marco institucional nominalmente democrático.

El marco legal se demuestra, entonces, crecientemente vaciado de toda legitimidad y pertinencia en el transcurso de la novela, lo que produce una transformación del personaje central, el burócrata leguleyo con aspiraciones anacrónicas de intelectual letrado, cuando se ve cada vez más incluido en la trama que pretendía solamente entender y resolver. Este desborde ocurre simultáneamente en varios niveles. En el primero, se da un desfasaje entre discurso e institución en el que el propio ejército y la policía consideran este marco puramente nominal o contingente. Esto crea en la novela un retrato del abuso del poder y de la corrupción peruana que contrasta coloridamente con el personaje central, obsecuente seguidor de la ley. En un segundo nivel, en vez de descifrar las pistas de los asesinatos, el fiscal Chacaltana va dándose cuenta de que la investigación misma parece estar marcando la trayectoria de los asesinatos; es decir, que sus procedimientos legales trazan el camino de la ilegalidad, ya que luego de que el primer cuerpo del delito desata la investigación, los muertos son todas personas con las que él había hablado. Este nivel explota la figura del perseguidor perseguido, potenciando entonces el interés de la 
trama detectivesca. Pero fundamentalmente, en un tercer nivel, los asesinatos, plagados de signos excesivos e inexplicables y posiblemente ancestrales, parecen desbordar el marco de la legalidad estatal representada por el fiscal, para remitir a un orden preestatal. Este es el nivel mágico-realista de la trama, que tiñe los asesinatos de un carácter cultural ancestral a la vez cristiano y andino, de un misticismo milenarista que aparece en algunas secciones como una voz impersonal e inconsciente $(62,168-169,225-227$, etc. $)$.

Este último nivel es fundamental en muchos sentidos. Le da por supuesto un localismo profundo a la novela, al intentar una representación del sistema de referencias de un Perú ancestral, al que manifiestamente Sendero se opuso, y sin embargo la novela parece resolver este antagonismo planteando un continuo. Cada asesinato está de este modo excedido por un más allá de la razón, del límite entre la vida y la muerte, mediante marcas en el cuerpo o en lo que queda de él, que se ofrecerían así al desciframiento. Este fondo irracional constituye también el lugar mismo de la legitimación de la constante violencia simbólica del Perú oficial, encarnado en varios personajes, al marcar al sujeto andino como irrecuperable: opaco a la razón, apegado a creencias intransigentes, remoto e impenetrable, carente de sentido de responsabilidad individual, etc. Constituye el discurso oficial de la cultura criolla representada vastamente en la novela, personificada en figuras como el policía y el cura, etc. Pero en última instancia, todo este aprendizaje en el fondo atávico que el fiscal Chacaltana debe realizar (que constituye también un aprendizaje de su propio pasado, ya que él creció y se educó en Lima pero es originario de Ayacucho) es una pista falsa - y lo mítico se revela como una escenificación para ocultar lo político o lo llanamente criminal, reforzando estratégicamente estereotipos sobre el sujeto andino-.

La serie de asesinatos parece remitir, por su mero exceso mesiánico, a métodos senderistas, y hay episodios en que aparece Sendero en actividad (amenazante, pero en última instancia inofensivamente), a pesar de que todos parecen sostener el discurso eufórico de la pacificación lograda - que responde a la propaganda fujimorista de haber vencido al terrorismo, incentivada, en la novela y en la historia, también por los intereses comerciales de la industria del turismo y la sintonización del Perú con la globalización-. Todo acontece sobre el fondo de los festejos de la Semana Santa, que funciona por un lado como una tradición reacondicionada para el espectáculo turístico y por el otro como suelo místico sincrético ultraterreno desde donde se lee la serie de asesinatos, ya que parece alimentar también el sistema de referencias inscriptas en los restos de las víctimas. El aprendizaje del fiscal consiste en empezar a leer los signos en los cuerpos a través de estos múltiples sistemas de referencias. 
Pero como en el Borges de "La muerte y la brújula", el substrato místico de los crímenes es una mera artimaña para desconcertar, una pista falsa para implicar a los senderistas, cuando el motivo de los crímenes, o del crimen que luego desencadenaría todos los demás asesinatos, es otro: acallar al más sangriento de los perpetradores, al Perro Cáceres, militar que parece no respetar el acuerdo tácito de mantener un bajo perfil, de permanecer en las sombras, de no llamar la atención, como condición para el olvido. Los asesinatos se terminan revelando entonces como una especie de estrategia del comandante Carrión, un militar envuelto en torturas y masacres, para no ser descubierto, para pasar desapercibido. Para mantener un perfil bajo y producir el olvido requerido por el pacto de silencio dentro de la retórica oficial del triunfo sobre Sendero, Carrión se ve obligado a matar a otro perpetrador, cuya conducta irreverente podría delatarlos a él y a otros integrantes de las fuerzas de seguridad, lo cual inicia una serie de asesinatos calculados con la explícita intención de borrar las huellas, pero que solo logran diseminar las sospechas que intentaban cubrir. El cadáver que desata la investigación y con cuyo hallazgo comienza la novela, carbonizado hasta el extremo, resulta ser entonces el del Perro Cáceres. Cuando el fiscal logra dar con este hilo de la trama, ya es demasiado tarde, porque ha perdido la cabeza, desbordado todo marco de pensamiento que hasta ese momento lo sostenía, y ha menoscabado todo soporte institucional en su incapacidad para sumarse a la razón cínica de sus pares.

En muchos sentidos, el Perro o su cuerpo (del delito) carbonizado, que atraviesa la trama, tiene una relación siniestramente especular con el protagonista. Efectivamente, lo que lleva a la muerte al primero y a la locura al segundo es el celo excesivo que los conduce a no lograr acomodarse a la razón cínica que perpetúa el sistema. Mientras el fiscal confía en la aplicación del procedimiento legal sin atender al hábito constituido, es decir, a las reglas tácitas que dictan en qué condiciones el acuerdo oficial es el de no respetar la ley, el extorturador se piensa indefectiblemente como un soldado de la patria en orgulloso cumplimiento de su deber, y persiste en defender públicamente las masacres cuando el acuerdo implícito, la condición de la pacificación, era el de sumergirlas en el olvido ${ }^{8}$.

Ciertos aspectos de Abril rojo parecen ser el espejo invertido de Lituma en los Andes (1993) de Mario Vargas Llosa ${ }^{9}$. En esta novela, la violencia está vaciada de todo contenido político y es "explicada" desde el marco de un Perú profundo

8 Esto podría denominarse, siguiendo a Michael Taussig, el secreto público, es decir, saber qué no saber.

9 La obra de Vargas Llosa fue traducida al inglés por la misma traductora de la novela de Roncagliolo, Edith Grossman. 
y siniestro que incluye elementos canibalísticos y sacrificiales. Sendero, a pesar de su rechazo explícito de toda creencia religiosa, sería una manifestación del atavismo andino ${ }^{10}$. Si bien la concepción de un Perú profundo y ahistórico es en Abril rojo una pista falsa, la novela acompaña entonces al fiscal Chacaltana en su exploración del substrato mítico o simbólico (desde la leyenda del Inkarri, pasando por un resumen de "El sueño del pongo" de Arguedas hecho por un senderista preso, hasta el análisis de la religiosidad indígena realizado por el cura) y satisface así la curiosidad antropológica y/o turística del lector. Finalmente, revela que todo ese despliegue se trató nada más que de un encubrimiento del asesinato político cuya víctima fue alguien que, como en las series detectivescas, sabía demasiado (por ser él mismo el victimario) y no tenía intención de callar. En cierto sentido, la novela redobla de esta manera la estrategia del encubrimiento del asesino, y en vez de profundizar en las consecuencias de la violencia política busca que el lector se pierda en pistas coloridas, aunque falsas. Es decir, los términos desplegados en la narración apoyan la división entre la modernidad y sus otros atávicos. La novela postula una continuidad entre Sendero y las creencias y prácticas populares como la del Inkarri y la misma religiosidad sincrética andina, que está explicada durante todo el relato por un mediocre leguleyo aculturado que es su antihéroe protagónico, y que en su posición de sujeto pedagógico reproduce internamente la posición del lector, que aprende algo sobre el Inkarri, Arguedas, la Semana Santa en Ayacucho, etc. Si en la novela los crímenes se descubren, a pesar de las apariencias, no en continuidad con la cultura y las creencias populares sino como una serie de venganzas para silenciar y enterrar un pasado inconveniente, la larga duración de la violencia después del fin de la violencia está explicada a través de este fondo atávico o "utopía arcaica", para utilizar la expresión del mismo Vargas Llosa.

La novela educa así al lector en un acervo cultural que la novela misma desprecia como la expresión o el síntoma de la violencia ancestral, y nunca en la articulación de una solución política. El relato parece llamar a la acción a una comisión de la verdad que sería promulgada poco más de un año después de los acontecimientos ficcionales de la novela, con un mandato amplio de investigar violaciones de derechos humanos ocurridos entre 1980 y noviembre del 2000. Efectivamente, entre un discurso oficial que resalta la victoria militar, un aparato legal puramente formal y parcial, y una estrategia de silencio tácito y

10 Para una interpretación de esta novela en el contexto de las ideas de Vargas Llosa y de su propia actuación en una comisión anterior (que investigó los crímenes de Uchuraccay), véase el artículo de Jean Franco. 
perpetuación de la violencia simbólica, lo ausente en la novela es la inmensa mayoría de ayacuchanos atrapados entre fuegos cruzados. En la historia, la comisión peruana pondrá énfasis en este aspecto, ya que se concibe como agente de una reparación histórica más profunda que la que supondría una concepción liberal de los derechos violentados del individuo, pues reconocería y ampliaría su espectro a los derechos comunales y pertinentes a las culturas nativas (sin duda en consonancia con la búsqueda de un nuevo consenso internacional cuya manifestación más clara es la Década Internacional de los Pueblos Indígenas declarada por las Naciones Unidas en 1994). La comisión entonces se concibe como facilitadora de la emergencia de verdades que trascienden las que pueblan la novela, y pondrá énfasis en las audiencias públicas (testimonios orales) y en un caleidoscopio de modalidades narrativas y/o expresivas populares y $\operatorname{artísticas~}^{11}$.

Si esta estrategia logra o no democratizar la esfera pública y la medida en la que tal intervención en el imaginario es una forma de justicia y reparación son preguntas abiertas; pero es el modo en que la comisión reemplaza una concepción de la cultura popular como utopía arcaica para leerla como redefinición de la cultura democrática. Claro que puede argumentarse que este privilegio de la esfera cultural, en tanto se ofrece como ámbito de confrontación y enjuiciamiento, esconde la inacción y el desinterés de la clase política y del poder judicial por iniciar verdaderos procesos legales. El trabajo de artistas y teatreros junto a la comisión peruana ha recibido mucha atención de la academia ${ }^{12}$, sin duda por su

11 Como un banco de imágenes fotográficas, una exhibición de fotografías acompañada por un libro con una selección de fotos (Yuyanapaq: Para recordar. Relato visual del conflicto armado en el Perú. 1980-2000). Véase también el artículo de Milton sobre la comisión peruana que se basa en el análisis de modos de expresión populares. "People's desire to contribute to a public history and to record their experiences can be found outside the CVR in films by the Ayacuchano filmmaker Palito Ortega Matute and others, in regional artistic traditions such as the hand-painted wooden boxes and boards (retablos and tablas) by Ayacuchano and Sarhua artists depicting violence, the lyrics of folk songs (such as huaynos and pumpin) that give testimony to the abandonment of natal lands and the disappearance of loved ones, local memory sites that mark common graves and massacres, and abandoned villages recently reinhabited, for instance Uchuraccay. In this article, I have chosen to look specifically at three modes of truth telling during the months around the submission of the TRC report: humor, performance, and art. For examples of humor, I have drawn from editorial cartoons that appeared in leading Peruvian newspapers in the weeks before and after the Final Report. The performative events described here took place on the eve of the public presentation of the Final Report in the city of Huamanga, the capital of Ayacucho. Examples of artistic expression come from an art contest held by an NGO in Ayacucho and from retablos by Edilberto Jiménez on display during the Final Report" (Milton 9).

12 Véase, por ejemplo, la extensa bibliografía sobre el grupo cultural Yuyaychkani, que participa activamente en las audiencias de la comisión con intervenciones teatrales específicas. 
calidad y complejidad, pero también por su visión optimista de la producción cultural como herramienta o capital disponible pasible de ser convocado como agente de intervención social ${ }^{13}$. Pero lo que esta utilización del arte con fines didácticos, terapéuticos y comunicacionales en última instancia señala es la performatividad de las comisiones mismas. Efectivamente, el carácter performativo de las comisiones de la verdad no es una manifestación casual ni local; algunas de ellas, como la sudafricana y la peruana, se ofrecen a sí mismas como sustituto (de las víctimas, de la sociedad civil, de los perpetradores, etc. $)^{14}$. Sin duda, toda instancia legal es performativa en más de un sentido, desde los protocolos escénicos del procesamiento, pasando por los actos de habla que produce una sentencia, hasta el carácter espectacular del castigo. Pero las comisiones, con una relación laxa con el poder, y con una función no estrictamente ligada a la capacidad de llevar a juicio, sin conexión directa entonces con la fuerza de la ley, son fundamentalmente dependientes de la adjudicación pública contingente y renovada de cierto poder simbólico. Esto constituye su frustrante limitación pero también el carácter siempre particular y específico de su intervención.

Otra novela peruana, La hora azul de Alonso Cueto, también se puede leer como un relato en donde el hábito, es decir, las reglas implícitas, los sobreentendidos de la cultura oficial del Perú contribuyen a la perpetuación de una violencia que en su expresión más espectacular se traduce en violencia política, pero que se sostiene en el día a día, el de las relaciones domésticas, laborales, etc. ${ }^{15}$. Adrián Ormache, un exitoso abogado limeño, se ve cada vez más implicado en aquello que toda su posición social y su educación parecen diseñadas para mantener a una simbólica distancia: el otro Perú, que puede encontrarse tanto dentro de su propia casa, en la figura de la sirvienta, como en la recóndita provincia de Ayacucho. Allí fue en donde su padre, el comandante Ormache, luchó como militar contra la guerrilla senderista; pero la historia de masacres y abusos, aunque de dominio público, parece no tocarle hasta que se entera de que su propio padre practicó la sistemática tortura, la violación y el asesinato indiscriminado de detenidos, algunos probadamente inocentes. De ahí la búsqueda y resignificación de trozos de su pasado, que lo vinculan con la memoria de un padre del que estaba alejado cuando vivía, y con excamaradas y subordinados de este; y la atrocidad abstracta y lejana se convierte súbitamente en parte del sistema de violencia que

13 Para George Yúdice se trata de una operación sobre el arte y la cultura, un modelo de legitimación, en directa relación con el modo de globalización que promueven las ONG.

14 Véanse las elaboraciones de Sanders respecto a la comisión sudafricana.

15 Véanse los comentarios de Žižek respecto al poder del hábito, como substrato de acuerdos tácitos más resistentes al cambio que las reglas explícitas (158-177). 
sostiene no solamente sus privilegios, sino también su misma identidad. La búsqueda incluye la ruptura de barreras sociales y geográficas, pero tanto las unas como las otras se encontraban tan cerca que la distancia que separaba a la vida del narrador de estas otras realidades cercanas era al mismo tiempo infinita e intangible.

Efectivamente, el narrador aprende luego de la muerte de su madre que esta, buena señora de la clase acomodada limeña cuyo casamiento con el joven militar había sido un error de juventud, había cedido a la extorsión para mantener el buen nombre de la familia y que no se develasen las atrocidades cometidas por su exesposo. Particularmente, la violación de una adolescente detenida por su padre, al parecer sin ninguna otra razón que su temprana belleza: Miriam, de quien el militar se habría enamorado, y a quien parece haber nombrado cuando agonizaba. En la búsqueda de Miriam por parte del abogado y en el develamiento de una verdad que su padre se llevó a la tumba y que solo ella conserva, se concentra el argumento; como si Miriam pudiese iluminar las razones de su propia victimización y la relación del investigador con la violación, que parece convertirse en el crimen central que resume una larga historia de violencia y exclusión.

El súbito y breve viaje del protagonista a Ayacucho, cuya función en el contexto de la investigación es mucho más ritual que práctica, se combina con la exploración constante a lo largo de la novela de barrios y aledaños limeños que representan para él el corazón mismo de las tinieblas. Es en esas periferias en donde Adrián Ormache encuentra a Miriam, un encuentro que amenaza con ser el comienzo de la ruina del abogado o quizá de su única vía de redención. Como sabe a quién busca pero no exactamente qué busca, el movimiento no se detiene allí, ni en el dinero que le comienza a facilitar cuando la encuentra, ni en las relaciones sexuales que tiene con ella, ni en su deseo de mostrarle a Miriam (quien vive en una zona poblada por ayacuchanos, periférica a Lima) una ciudad a la que solo una elite tiene acceso, ni en el constante interrogante que nunca satisface su curiosidad, ya que la pregunta parece ser imposible de formular. Todo acaba cuando ella muere o se suicida, dejándolo tácitamente como tutor de su hijo Miguel, a quien el abogado parece reconocer ahora como a su medio hermano y a quien, a pesar de la inicial reticencia del niño, comienza a sustentar económicamente y a prestar apoyo psicológico y emocional. La novela termina cuatro años después de las revelaciones que le dan comienzo, y con una frase emitida por el ya adolescente Miguel: "Quería agradecerle — dijo-. Agradecerle. Nada más" (303).

La hora azul es entonces una novela no solo de reconciliación, sino también de reparación y redención; una redención que ocurre en el ámbito doméstico y 
psicológico. Dinero y reconocimiento son la materia prima de la reparación porque constituyen la sustancia con la que se adjudica socialmente el valor, en una historia que sugiere al mismo tiempo que esa reparación se enfrenta con una carga irreparable que Miriam lleva hasta la muerte, cuya causa queda indefinida entre el suicidio y el ataque al corazón. Efectivamente, la reparación es tan necesaria como necesariamente insuficiente e inadecuada. Llega demasiado tarde, tanto la víctima como el victimario aparecen desplazados y sublimados (de Miriam a Miguel, de padre militar a hijo abogado) y el daño no tiene equivalencia, y todo intento de plantear un sistema de equivalencias solo acentúa la injusticia inicial. Es claro que la ley queda sintomáticamente como un mero instrumento de la minoría a la que el abogado pertenece y a la que presta sus servicios; pero al mismo tiempo, los desvelos del abogado representan no un esfuerzo legal sino un intento de intervenir en la estructura de creencias y acuerdos tácitos de la vida cotidiana, de los que sobran ejemplos en la novela, que reproducen y legitiman la violencia simbólica, la exclusión y el silenciamiento. Es aquí donde la narración señala el eslabón roto entre cultura y derecho - un eslabón que la democracia peruana no logró nunca componer, ya que no hubo procesos penales derivados de la investigación de la comisión - que determina la impotencia, la modestia, la poca monta de las acciones reparativas del protagonista, cuyo mundo simbólico, familiar, social, que parecía amenazado, se recompone sin mayores consecuencias. Y sin embargo, el carácter íntimo y familiar de la reparación da la impresión de ser la condición de posibilidad para que la intervención simbólica de la comisión se materialice en un legado efectivo. Un legado que en la novela se transmite lateralmente, en el contexto de estos dos improbables hermanos, como alternativa para remediar un legado paterno que se perpetúa solo con base en su condición obscena.

Terminaremos reflexionando sobre Insensatez (2004), del hondureñosalvadoreño Horacio Castellanos Moya, ya que quizás se trata de la novela que más claramente explota, en los dos sentidos de utilizar y destruir con violencia, el marco de la verdad y la reconciliación, y los usos de este marco tanto en el ámbito del imaginario nacional como transnacional. La obra está narrada en la voz de un hombre centroamericano contratado como corrector de estilo de un informe de la comisión de derechos humanos de otro país centroamericano no mencionado, pero que a todas luces es Guatemala. El informe, patrocinado por la iglesia, recoge testimonios de víctimas de la violencia del ejército contra una población mayoritariamente indígena. El narrador nunca expresa ninguna simpatía por la causa para la cual trabaja, ni hacia el programa del catolicismo progresista que presta su estructura institucional para la elaboración del informe, ni por la 
causa humanista de los profesionales internacionales de los derechos humanos que pueblan el relato (un entusiasta judío neoyorquino, un progresista militar uruguayo, dos sensibles psicólogas españolas). Las pasiones del narrador son absorbentes, y consisten en cobrar los cinco mil dólares acordados por su trabajo, llevarse a alguna de las españolas a la cama, y lidiar con su propio miedo a perder su vida a manos de paramilitares guatemaltecos $\mathrm{u}$ otras fuerzas oscuras, o del novio de alguna de sus conquistas sexuales que estaría también conectado a las fuerzas de seguridad. Al comienzo, ni la historia abierta del genocidio indígena ni la importancia social de difundir las atrocidades que pueblan el relato forman parte de sus desvelos. Indiferente o escéptico, estas causas no son su causa, esta historia no lo afecta, y este dolor en principio ajeno no lo toca.

El narrador de nuestra novela no es entonces ni testigo, ni juez, ni abogado; y en su perspectiva impregnada de misoginia y racismo, carece de fundamento moral para pedir, como Neruda lo había hecho desde la posición segura del intelectual resistente, castigo. El narrador, un intelectual desencantado, considera y descarta el programa de redención histórica que marcó la agenda latinoamericanista. Imagina una novela que podría escribir, salvando cierta deuda con la literatura latinoamericana, basada en el documento sobre el que trabaja. Se trata de la ficcionalización de un testimonio, y la novela sería protagonizada y narrada por el alma en pena del registrador civil del pueblo de Totonicapán, que se opone a entregar a las autoridades los nombres de los muertos, para que no sean contados como votos a favor de la perpetuación en el poder del (ex) dictador general Ríos Montt. Hay una tensión entre región y centro, del individuo contra el estado, y de la memoria frente a la historia oficial, en una serie de oposiciones con las que se ha articulado la literatura latinoamericana del periodo clásico $^{16}$ : como en Rulfo, en Fuentes, o en García Márquez - "que el realismo mágico no me es por completo ajeno", comenta el narrador con ironía (73)-, los muertos conviven con los vivos en una proposición que coloca a la literatura como mediación y simbólica conciliación entre versiones desencontradas de la historia, o de redención de historias negadas. En pocos parágrafos Insensatez anda y desanda el camino de esta genealogía literaria hasta formar su reverso negativo, ya que el narrador considera al registrador civil —el protagonista ficcional de la novela que planea (no) escribir-un pobre idiota que merece que le destrocen la cabeza como un coco y que sus dedos sean amputados uno por uno, ya que no entiende una regla básica de convivencia, y es que el registro civil a su cargo está en función del poder militar en cuanto este lo confisca para sus fines. Y además,

16 Tomo esta graciosa expresión de Reinaldo Laddaga. 
"a nadie en su sano juicio le puede interesar ni escribir ni publicar ni leer otra novela más sobre indígenas asesinados" (74). Lo interesante para nuestros fines es que la agenda de derechos humanos y las instituciones que la sostienen se van revelando a lo largo de la novela como la condición misma del mentado "sano juicio" del testigo, una forma de acercamiento a la alteridad pero a condición de hacer oídos sordos al dolor y al trauma.

Porque a pesar del agresivo cinismo que el narrador exhibe, de su descreimiento de las buenas intenciones de los activistas, de su indiferencia a lo que aparece a medida que avanza el relato como una masacre atroz dirigida a exterminar a la población indígena, está profundamente impactado por frases sueltas que recoge directamente de los testimonios, testigos y víctimas, frases que le hacen recordar la poesía de Vallejo y que anota en una libreta, para luego leérselas en voz alta a sus bien intencionados pares, que sin embargo quedan perplejos y ostensiblemente indiferentes frente a la materia lingüística del testimonio. La novela misma se inicia con una de estas locuciones ("Yo no estoy completo de la mente"), las que a pesar de estar en constante circulación y transcripción (del testigo al informe, al cuaderno, a la novela) forman como una roca dura cuya materialidad se resiste a ser escuchada, no logra ser integrada en ningún contexto.

Lo traumático para el narrador es ser testigo involuntario de la indiferencia, no hacia el sufrimiento indígena, sino hacia un fondo inasimilable al que nada le hace justicia, ni las mejores intenciones de las psicólogas (cuya manifiesta intención es "ayudar a los indios a hacer el duelo"), ni el cura defensor de los oprimidos, ni el escritor latinoamericanista. Hay una total división entre quien aprecia el poder revulsivo de estas frases pero no siente ninguna solidaridad política con los indígenas que las emiten (por ejemplo "Después vivimos el tiempo de la zozobra" o "Que siempre los sueños allí están todavía") y aquellos cuya buena conciencia política es incuestionable, pero a quienes estas frases producen una total y absoluta indiferencia. Against literature: el problema podría sugerir una división entre estética y ética, entre estética y política, si se piensa que la recepción poética de estas frases captura la capacidad de movilizar políticamente, un cariz estético que despierta una sensibilidad autotélica. La estética funcionaría a otro nivel como anestética, adormecimiento de la capacidad de generar una respuesta. Pero creo que mucho más interesante es pensar cómo la novela se pregunta sobre las condiciones de posibilidad de una intervención poética que es al mismo tiempo una interpelación política, que podría convocar una respuesta ni paternalista (los profesionales de los derechos), ni piadosa o caritativa (la iglesia humanista).

El juicio del protagonista se va desmoronando en dos frentes simultáneos, el de la repetición compulsiva de lo que lee y escucha, su performance poética 
que lo desvive, y el de la intuición indeterminada de estar bajo constante amenaza de muerte. Son los dos Otros, el Otro de la alteridad y el Otro de la autoridad, que tienen para el narrador carácter traumático, que lo acosan simultáneamente. El miedo a la retaliación, a ser objeto de una violenta venganza, articula también una verdad desplazada al presentir una amenaza que se revela cuando es asesinado el obispo bajo cuyo auspicio se confecciona el informe ${ }^{17}$. Dos modos de la insensatez, dos modos de la verdad, se cruzan entonces en el campo de batalla de esta subjetividad acosada: la insensatez paranoica, por la cual se coloca como el blanco mismo de la cadena conspirativa, ese miedo que lo instituye y que le presta una sólida respuesta a la pregunta por su lugar en el Otro; y la insensatez esquizofrénica, que lo hace receptor de las voces sueltas de otros, voces que no se integran al régimen del presente y que permanecen como piezas escindidas de un espejo roto $^{18}$. Y el protagonista se ve obligado a huir constantemente para mantener su frágil cordura, de su país de origen a Guatemala, al comienzo de la narración, y de Centroamérica a Alemania, al final. La repetición fragmentada y compulsiva de las voces testimoniales es un modo de transmitir una verdad y denunciar su imposibilidad: que el derecho básico es el derecho a hablar y a participar de una comunidad de hablantes, y que esto es ya una invitación a la emergencia de lo inesperado; un derecho existencial que ninguna comisión puede garantizar y que el texto escrito del informe parece de hecho cancelar ${ }^{19}$.

La materialidad sonora del testimonio afecta el orden de lo sensible, y lo estético es redefinido como el punto en que el dolor de los demás nos toca, nos nombra, y al hacerlo nos incluye en su escena, a la que permanecíamos ajenos. En todo caso, este sujeto insospechado está llamado a ser testigo, sin haber decidido serlo, y es testigo porque es tocado desde el otro lado de la alteridad. A medida que transcurre el relato, estas voces en principio extrañas pasan a formar parte de su repertorio simbólico, y el narrador se convierte de sujeto interpelado por estas frases de sentido esquivo en un portador incómodo de sentencias que nombran, siempre parcial y lateralmente, su situación: como "hay momentos en que tengo ese miedo y hasta me pongo a gritar" (129) o "Que siempre los sueños allí están todavía" (123). La voluntad de transparencia

17 En una referencia, sin duda, al asesinato del obispo Juan Gerardi en abril de 1998, dos días después de la entrega del informe de Guatemala: nunca más.

18 La paranoia preserva simbólicamente la identidad al marcar una frontera infranqueable y al mismo tiempo peligrosamente porosa, una separación radical entre el yo y el Otro proyectado como una unidad compacta, lógica, una "otredad monolítica" que puede aplastar al sujeto (Bersani 189).

19 Esta perspectiva del derecho de hablar se basa en Jean-François Lyotard. 
judicial y la referencialidad demandada a los testimonios se contraponen a su fuerza poética, una fuerza que para el narrador remite a un único lugar en el discurso latinoamericano: Vallejo. Si bien la referencia a Vallejo es un modo de inscribir lo heterogéneo en una tradición conocida, si bien el cholo del Perú es lo único que posiblemente puede prestar un nombre al castellano roto de los indígenas de Guatemala, el significante "Vallejo" es movilizado, no para agrupar una nueva identidad, sino más bien para referirse a eso otro que constituye la literatura y que no es literatura, y que a la misma literatura le resulta incomprensible, como un monstruo que la acosa, que la dicta. Pero también "Vallejo" es eso que constituye los derechos humanos, que los habita, y que no son los derechos humanos, sino esta alteridad intraducible, el derecho a decir algo que los derechos humanos no pueden decir de antemano, el derecho a tener derechos.

\section{Obras citadas}

Alarcón, Daniel. Lost Gity Radio: a novel. Nueva York: Harper Collins Publishers, 2007. Avelar, Idelber. The Untimely Present. Postdictatorial Latin American Fiction and the Task of Mourning. Durham; Londres: Duke University Press, 1999.

Bersani, Leo. The Culture of Redemption. Cambridge, MA: Harvard University Press, 1990.

Castellanos Moya, Horacio. Insensatez. México: Tusquets, 2004.

Cueto, Alonso. La hora azul. Barcelona: Editorial Anagrama, 2005.

Domingo, P. y R. Sieder. Rule of Law in Latin America: The International Promotion of Fudicial Reform. Londres: Institute of Latin American Studies, 2001.

Franco, Jean. "Alien to Modernity. The Rationalization of Discrimination". A Contracorriente 3.3 (primavera de 2006): 1-16.

Franz, Carlos. El desierto. Santiago de Chile: Sudamericana, 2005.

Ignatieff, Michael. Human Rights as Politics and Idolatry.

Princeton: Princeton University Press, 2001.

"Informe final". Comisión de la Verdad y Reconciliación 28 de agosto de 2003. Web. 16 de julio de 2014.

Laddaga, Reinaldo. Literaturas indigentes y placeres bajos: Felisberto Hernández, Virgilio Piñera, fuan Rodolfo Wilcock. Rosario: Beatriz Viterbo, 2000.

Loveman, Brian y Elizabeth Lira. "Truth, Justice, Reconciliation, and Impunity as Historical Themes: Chile, 1814-2006".

Radical History Review 97 (invierno de 2007): 43-76.

Lyotard, Jean-François. "The Other's Right". On Human Rights. The Oxford Amnesty Lectures 1993. Eds. S. Shute and S. Hurley. Nueva York: HaperCollins, 1993. 135-147. 
Milton, Cynthia. "At the Edge of the Peruvian Truth Commission: Alternative Paths to Recounting the Past". Radical History Review 97 (invierno de 2007): 3-33.

Navarro, Vincenç. "Spain is different o la impunidad mantenida". El País 17 de diciembre de 2008. Web. 16 de julio de 2014.

O'Donnell, Guillermo. "Polyarchies and the (Un)Rule of Law in Latin America: A Partial Conclusion". The (Un)Rule of Law and the Underprivileged in Latin America. Eds. J. E. Méndez, G. O’Donnell y P. S. Pinheiro. Notre Dame, IN: University of Notre Dame Press, 1999.

Rancière, Jacques. "Who Is the Subject of the Rights of Man?". South Atlantic Quarterly 103.2-3 (2004): 297-310.

Richard, Nelly y Alberto Moreiras. Pensar en/la postdictadura. Santiago de Chile: Cuarto Propio, 2001.

Sanders, M. Ambiguities of Witnessing: Law and Literature in the Time of a Truth Commission. Stanford: Stanford University Press, 2007.

Sieder, R. et al., eds. The fudicialization of Politics in Latin America. Nueva York: Palgrave Macmillan, 2005.

Taussig, Michael T. Defacement: Public Secrecy and the Labor of the Negative. Stanford: Stanford University Press, 1999.

Vargas Llosa, Mario. Lituma en los Andes. Barcelona: Planeta, 1993.

Volpi, Jorge. En busca de Klingsor. Barcelona: Seix Barral, 1999.

Yúdice, George. The Expediency of Culture. Uses of Culture in the Global Era. Durham; Londres: Duke University Press, 2003.

Žižek, Slavoj. Violence. Six Sideways Reflections. Nueva York: Picador, 2008. 